\title{
Critique and complexity: presenting a more effective way to conceptualise the knowledge adoption process
}

\author{
Chris Brown* \\ London Centre for Leadership in London, Institute of Education, University of London, London, UK \\ (Received 29 March 20I2; final version received I4 June 20I2)

\begin{abstract}
The process of 'knowledge adoption' is defined as the means through which policy-makers digest, accept then 'take on board' research findings. It is argued in Brown, however, that current models designed to explain knowledge adoption activity fail to fully account for the complexities that affect its operation. Within this paper, existing frameworks are explored and critiqued, and an alternative approach is presented. It is argued that this alternative conceptualisation provides a more effective explanation of the knowledge
\end{abstract} \\ adoption process and significantly improves on extant work in this area.
}

Keywords: evidence-informed policy; knowledge adoption; models of knowledge adoption; factors affecting knowledge adoption

\section{Introduction}

Much has been written in terms of how research can enhance policy (e.g. Oakley 2003; Temple 2003), and it has been suggested that there are a number of key points at which research can assist the policy-making process: for instance, by aiding the identification of a problem, by helping to create, form or steer the public agenda or by aiding (or inspiring) policy directorates in the development of their initiatives (Nutley, Walter, and Davies 2007; Perry et al. 2010; Brown 20II). The means through which policy-makers encounter and engage with evidence have also been conceptualised in a variety of ways, for example, via the notion of 'knowledge exchange' defined by the Canadian Health Services Research Foundation as 'a collaborative problem-solving between researchers and decision makers' or the concept of 'knowledge mobilization' described as a process of strengthening the connections that exist between research, policy and practice (Cooper and Levin 2010; Levin 20 I I). I use the phrase 'knowledge adoption' to depict the process, in all its complexity, of policy-makers digesting, accepting and then 'taking on board' research findings; noting their relevance, benefits or future potential (see below and Brown 201 I). I also suggest that researchers' greatest chance of influencing policy is by facilitating a process of knowledge adoption at those points in the policy process where policy-makers will be most receptive to evidence or new ideas.

Current thinking as to how the knowledge adoption process might be expressed or most effectively undertaken is set out in a number of extant models. This paper argues, however, that these models fail to address a number of issues that are central to any

*Email: christopher.brown@mac.com 
fundamental conceptualisation of knowledge adoption or to its successful realisation. For example, that, individually, models fail to capture fully the complexities of the knowledge adoption process; that there is no satisfactory over-arching theory that accounts effectively for the process of research adoption and how it might be improved; that existing models fail to reflect the social nature of knowledge adoption or the motivations of social actors to engage in such activity; that the models proposed to date do not differentiate between the varying contexts that researchers may find themselves in; extant models also fail to explicitly differentiate between the myriad of analytical levels at which knowledge adoption operates; finally, it is argued that current models omit to differentiate between instrumental and conceptual uses of knowledge.

The aims of this paper, therefore, are to describe existing models of knowledge adoption and demonstrate how such models have been substantially critiqued; to illustrate how this critique has necessitated the development of a new model of knowledge adoption and how this model was derived from a configurative systematic review of existing literature; and to illustrate the implications of the model for the notion of evidence-informed policy-making more widely. This paper is derived from a project undertaken between 2009 and 20II. Its focus was (i) to review existing conceptualisations of knowledge adoption and, in particular, to examine explanatory models of how evidence feeds into the policy-making process (specifically with regard to the education sector in England and Wales) and (ii) to put forward suggestions for how knowledge adoption processes might be effectively implemented by researchers, with a view to increasing the use of evidence within policy making.'

\section{Methodology}

The analysis presented is derived from a review of extant literature. The aim of the review was to provide an overview of existing theory and an understanding of the type of empirical studies previously undertaken in this area. Whilst systematic in approach, the review did not replicate all of the steps systematic reviews employ: this was because the primary requirement of the review was for it to provide general understanding, rather than a comprehensive assessment of empirical evidence. This corresponds with a configurative rather than aggregative approach to reviewing literature (Sandelowski et al. 201I; Gough, Oliver, and Thomas 2012). In other words, one that enables the author to ascertain key themes in a given area, so that they can be combined with an explanatory theoretical framework.

The focus of the study was the education sector in England and Wales. The topic area involved, however, (knowledge adoption) has salience for, and has been studied within, other policy sectors and countries. As such, the screening criteria for the review were relatively wide in their scope: studies had to involve the knowledge mobilisation process, but could be theoretical or empirical in nature. For example, they could discuss how knowledge mobilisation has been realised in actuality or arguments as to how it might be realised. Studies were required to be in English and to relate to policy systems that had similarities to that of England and Wales (for example: Canada, Australia, USA, etc.). Papers or studies relating to policy sectors other than education were included. Studies relating solely to evidenceinformed practice were excluded.

Literature was initially searched for in two ways: (i) A search of four prominent databases (JSTOR; Academic Search Complete; Web of Knowledge; IngentaConnect) using search terms synonymous with that of 'knowledge exchange'. These included, for example, 'knowledge mobilisation', 'knowledge transfer' and 'knowledge brokering' and were taken from the definitive list provided on the University of Toronto's Research Supporting Practice in Education website. ${ }^{2}$ and (ii) Recommendations on seminal literature were also sought 
from colleagues, authors identified from the search above and experts in the fields of evidence-informed policy and knowledge adoption. The references cited by the authors of these studies were then reviewed. Further literature was also obtained where these references detailed pertinent papers that had not been picked up in the first two approaches. Overall, these three approaches to sourcing literature, combined with the screening criteria, resulted in a total of 228 studies being reviewed. Further detail may be found in Brown (20II).

\section{Description and critique of existing models derived from current literature}

From the literature review, it was possible to identify a number of models currently in existence, which seeks to explain the process of knowledge adoption, these are described below. The genealogy of these models illustrates how the perceived drivers of adoption have evolved over time: Mitton et al. (2007), for example, argue that the concept of 'knowledge transfer' dominated during the 1980s and 90s. This led early explanations of adoption, for instance the Demand Pull Model (Weiss 1979; Yin and Moore 1988; Rich 1991), to focus on one-way transfers or pushes of knowledge from researchers to policy-makers (who had specifically requested the research). After its initial development, the notion of Demand Pull was augmented by that of Producer Push (Lavis et al. 2003), highlighting the growing perception that active efforts on the part of researchers were also required in order to inform decision-making. Knowledge adoption thus also came to be viewed as a function of researcher engagement with potential audiences, and how accessible research messages were made to these audiences (i.e. the ways and means through which research is targeted at users).

The notion that pull and push alone could account for the adoption of knowledge was problematised, however, both by the conceptualisation of the Enlightenment Model (Weiss 1998) and through the development of the Two Communities Model (Amara, Ouimet, and Landry 2004). Within the Enlightenment Model, for example, knowledge adoption was conceived, not as a consequence of the findings of a single study or a body of knowledge, but from the percolation of evidence into the policy-making domain, causing policy-makers to think differently about particular issues over a period of time. The Two Communities Model, meanwhile, assumed that a cultural gap exists between policy-makers and practitioners on one hand and academic researchers on the other. As a consequence, the model advanced the notion that a lack of understanding exists between these 'two communities', leading to low levels of communication (and so knowledge adoption) between them. Mitton et al. (2007) observe that, as a result of the issues raised by both the Enlightenment and Two Communities Models, later conceptualisations of knowledge adoption were grounded in the idea that the successful adoption of knowledge requires lengthy interaction rather than one-way conversation. Likewise, Nutley, Walter, and Davies (2007) posit that the findings of research do not 'speak for themselves', they are interpreted and that this happens best through dialogue and engagement. As a result, models such as the Interaction/Communication and Feedback Model (Dunn 1980; Yin and Moore 1988; Nyden and Wiewel 1992; Oh 1997; Nutley, Davies, and Walter 2002; Amara, Ouimet, and Landry 2004) and the Linkage and Exchange Model (Lavis et al. 2006) were developed to explain knowledge adoption as a dynamic, two way process.

At the same time other codependent or complementary models, developed in parallel, began to focus on individual aspects of the adoption process. For instance, the Organisational Interests Model (Amara, Ouimet, and Landry 2004) frames the argument that the size of organisations, their structures, the nature of their responsibilities and their needs may affect the propensity of professionals working within them to adopt and utilise or underutilise 
research. The Engineering Model (Amara, Ouimet, and Landry 2004) suggests that the effective adoption of research depends on the characteristics of the research findings. These include content attributes (such as compatibility, complexity, observability, trialability, validity, reliability applicability, etc.) and the type of research (basic-theoretical/applied, general/ abstract, quantitative/qualitative, particular/concrete and research domains and disciplines). Best and Holmes (20l0), meanwhile, argue that four interconnected factors: evidence and knowledge, leadership, networks and communications may best account for how knowledge is turned into action and that these warrant further exploration.

These models have also been subject to substantive critique. For example, the explanatory power of a number of them was tested empirically by Landry, Amara, and Lamari (2003) in a survey of 833 Canadian government officials. Landry et al. concluded that whilst more interactive factors appear to best explain research adoption, overall, the process is far more complex than these existing models might suggest. Estabrooks et al. too argue that there is currently no satisfactory over-arching theory to explain effective research adoption, with most models tending to focus on 'explanation rather than prescription' (2006, 26). These sentiments echo the work of Wingens (1990), who describes the explanatory power of knowledge adoption models as 'mediocre' whilst Cooper, Levin, and Campbell (2009) argue that they are conceptually inadequate and fail to reflect the idea that knowledge use is a social process. Finally, Mitton et al. $(2007,756)$ note that 'there is very little evidence that can adequately inform what [knowledge adoption] strategies work in what contexts'.

This critique is further augmented in Brown (20l I), where three key areas are examined. The first relates to current conceptualisations regarding the motivations of social actors to engage in knowledge adoption activity. It is contended that knowledge adoption is typically directed towards a goal or purpose (the 'what' of knowledge adoption); that there will be empirically observable actions geared towards achieving this goal (the 'how' of knowledge adoption) and specific motivating factors will drive policy-makers and researchers to engage in the actions they do (the 'why'). In applying this to existing models, it is clear that they often account for the 'how' and the 'what', but invariably fail to consider the 'why'. For example, the Demand Pull Model describes its 'what' as the demand for evidence by policymakers in order to aid in problem solving. No explanation is provided, however, in terms of why researchers are motivated to engage in this type of problem solving behaviour (and conversely, why some are not). The Interaction/Communication and Feedback Model, on the other hand, posits that interaction encourages knowledge adoption. Interaction can be considered a 'how'; that is, it is something that can be observed and is geared towards a goal. The 'why' of any interaction, however, would comprise the factors which account for this interaction (and the 'why' would also help explain what interaction is symptomatic of more generally: interaction, for example, is likely to be just of a number of types or families of actions, all directed towards achieving a desirable outcome). In failing to consider the motivations of social actors, these models also fail to account for the sociological nature, complexity and depth of factors which affect the knowledge adoption process and of potential actions which might enhance the efficacy of its operation. For instance, in terms of providing clues as to how knowledge adoption activity might be better incentivised or facilitated in future.

A second point of critique is that current models do not explicitly differentiate between the myriad of analytical levels at which knowledge adoption operates at or is affected: these include that of the individual policy-maker/researcher, of groups or organisations, or at the level of society more broadly. This distinction is important, however, because at these different analytical levels, very different factors of influence are likely to come into play. Such factors will range in nature from the specific actions that might be undertaken by 
researchers and policy-makers (as individual communicators of, or audiences for research), to issues of power relations, which operate at more macro levels (Foucault 1980).

Finally, current models of knowledge adoption fail to differentiate between the manifold range of impacts that research outputs might have on policy development. These are likely to range in nature from actual use; where tangible change occurs on the back of research findings, to one of 'enlightenment'; where outputs serve to enhance or add to users' perspectives on a given issue. Such impacts have been defined by Weiss $(1979,1982)$ as the 'instrumental' and 'conceptual' uses of research, respectively. In terms of policy development, examples of both instrumental and conceptual impact may be found in recent papers and studies; for instance, Taggart et al. (2008)'s description of the instrumental influence of the Effective Pre-School and Primary Education 3-I I longitudinal study. Levin (2008), meanwhilst, provides an example of conceptual use when he notes that the implementation of England's smoking ban (in 2007) can be contextualised in terms of the decades of peripheral, enlightenment type activity which preceded it. This differential is important since, in a complex policy-making environment, solely considering conceptual uses of knowledge is likely to lead to researchers developing fundamentally different strategies than those that might affect instrumental (or actual) use. For example, researchers seeking to further conceptual knowledge use might concentrate their efforts on how their research outputs are communicated; enhancing instrumental use, on the other hand, may involve researchers spelling out to policy-makers how given research can be used to improve a particular policy area.

\section{Factors affecting the success of approaches to knowledge adoption}

As a result of this critique, it is argued that existing models do not provide an effective basis for recommendations as to how researchers might better facilitate knowledge adoption; consequently, that this lack of pertinent underpinning theory necessitates the development of an alternative perspective on how knowledge adoption operates and how it might be facilitated. The development of this alternative perspective was subsequently addressed via a thematic analysis of the literature searched for and described above. The thematic analysis was focussed on identifying and grouping together the myriad of factors that affect the knowledge adoption process. As a result of this approach, two overarching themes were derived: the first encapsulates those factors that directly relate to the research to be adopted and to attempts to communicate research outputs by researchers. The second theme comprises those factors which impact upon how the findings from any given study are likely to be received by its audience. These initial themes are defined as internal and external factors, respectively. The principle implication of this distinction is that (i) researchers who are interested in informing policy are responsible, not only for managing their research approach and the interpretation of data, but also for (the internal) components which affect how they attempt to communicate their findings to policy-makers and (ii) Policy-makers, as audiences, meanwhile, are responsible for how evidence is received - the factors that affect reception are external to any given study but will still impact upon whether research messages will be taken on board.

Set out below is a brief summary of these internal and external factors; more detail about each may be found in Brown (20II). To begin with, the internal factors affecting knowledge adoption are regarded as:

(i) The nature of what is communicated: Lavis et al. (2003) argue that, in terms of content, policy-makers prefer to be presented with 'ideas' rather than pure data since 'decision makers rarely use a regression coefficient to help them solve a particular 
problem' (2003, 223). Likewise, it is suggested (Lindblom and Cohen 1979; Kirst 2000; Davies 2006; Campbell et al. 2007; Moore et al. 20II) that policy-makers are keen to receive 'straightforward' narratives or stories coupled with advice they can understand, with Court and Young maintaining that policy-makers can be convinced about a new approach if the story is simple and convincing enough.

(ii) Clarity of presentation: Nutley, Walter, and Davies $(2007,7 \mathrm{I})$ argue that 'presentation is key: research must be attractive ... and visually appealing'. In Brown (2009), a number of policy-makers I interviewed highlighted How the world's best performing school systems come out on top, produced by Barber and Mourshed (and published by McKinsey \& Co.) in 2007 as an excellent example of effective presentation. ${ }^{3}$ How the world's best ... is extremely 'stylised' in design and, as a result, it was suggested that the notion of 'clarity in presentation'; the look and feel of a piece of research is key to the effective and efficient communication of its findings (ibid). Reports do not necessarily have to take the 'Barber and Mourshed' approach, but there is a requirement for rigorous information that is also easy on the eye (and so, also on the brain).

(iii) The efficacy of the communication type: early studies such as that of Paisley (1993) suggest that new and emerging methods of communication will only be effective when used in conjunction with face-to-face interaction. This corresponds with the findings of a review by Lavis et al. (2003), the views of Levin (2008), Cohn (2006) and with the work of Davies (2006); all of which indicate that passive communication processes (for example, making research findings available via websites) are ineffective, while interactive face-to-face engagements between policy-makers and researchers are more likely to lead to research findings being acted upon (Innvaer et al. 2002; Campbell et al. 2007; Moore et al. 201 I).

(iv) The level of proactivity, contextualisation and tailoring: Levin (2004) argues that policymakers should be provided with the full range of evidence-informed options for policies. As a result, research findings should therefore be contextualised by and shown to relate to other evidence within the field. In Brown (2009), it is suggested that research contextualisation occurs as part of a wider suite of proactive interactions between government researchers and policy-makers; for instance, the majority of government researchers interviewed in that study provided examples of proactively engaging policy-makers in order to interest them in the findings of research; for example, through attempts to anticipate or understand the needs of policy-makers in a timely way and then tailor and/or position findings so that they had more relevance to a given policy setting or context. Lavis et al. (2003) also link contextualisation to the tailoring of content. They conclude that all audiences for a particular piece of evidence, as well as the environments in which they operate and the decisions for which they are responsible, must be well defined and understood in advance of any communication. Any findings to be delivered to that audience should then be suitably tailored.

The external factors derived from the literature review are:

(i) Inherent factors that comprise the policy-maker's knowledge 'mould' (Huberman 1990; Levin 2004): Here, it is assumed that, ultimately, it is in the gift of policy-makers as to which information they digest, or whether they choose to re-examine long-standing viewpoints. The adoption of evidence will thus necessarily depend upon whether those potentially acquiring new knowledge have specific reasons to take on board more information. For example, whether there exists uncertainty amongst 
policy-makers about an issue, whether they feel challenged about certain aspects of a particular problem, or whether they have insufficient existing information in a given subject.

(ii) The perceived credibility of the source by the policy-maker: Policy-makers' receptiveness to sources of evidence will also be a function of the reputations of those providing the research (Kirst 2000; Court and Young 2003; Landry, Amara, and Lamari 2003; Campbell et al. 2007; Nutley, Walter, and Davies 2007). The credibility or trustworthiness of the source of any evidence is therefore paramount, with Campbell et al. (2007) contending that credibility is a function of a number of factors, including the perceived bias of the researchers. Kirst (2000) also suggests that credibility is a direct result of whether knowledge transmitters are seen to have acknowledged expertise, which might include any previous experience they may have had in working within, or for, government.

(iii) The perceived quality of the evidence by the policy-maker: Both Campbell et al. (2007) and Nutley, Walter, and Davies (2007) suggest that policy-makers' perceptions as to the quality of a study will also affect any demand for evidence. The notion that 'quality' can exist as a tightly defined concept that might be easily applied to research has been contested, however, (e.g. see Ball 1995; Nutley, Walter, and Davies 2007), and it has been argued by some (e.g. Brown 20II) that more use should be made of Oancea and Furlong's (2007) model of quality. This considers a number of quality assessment criteria, including: methodological and theoretical robustness, use value and timeliness, the reaction to the research by policy-makers and practitioners and the cost effectiveness of the study.

(iv) General involvement by policy-makers in research studies: Council for Science and Technology (2008), Moore et al. (20I I) and Rickinson, Sebba, and Edwards (20II) suggest that user engagement is crucial to maintaining dialogue and the continuous flow of ideas, ensuring that projects remain relevant and at the forefront of policy-makers' thinking. Networks of policy-makers, practitioners and researchers are also regarded as an effective way of increasing the demand for research (Gilchrist 2000; Kirst 2000; Watson et al. 2002; Cooper and Levin 2010). This is because networks create ongoing social contact and dialogue, which help persuade policy-makers of the relevance of the evidence or issues, and so increase the chances that research might be used (Nutley, Walter, and Davies 2007).

(v) Access to policy-makers: In the absence of the active involvement of policy-makers in research projects, researcher access to them is vital. One example of researchers successfully accessing policy-makers is provided by the Effective Pre-School and Primary Education project undertaken by Sylva et al. (2007). Here, researchers involved with the study report that supportive organisational structures were established within the (as was) Department for Children Schools and Families (the study's commissioners) and that these structures enabled the study's findings to be communicated to them directly. Davies, Nutley, and Smith (2000) note that, in the absence of similar structures, gaining access to policy-makers may be problematic, especially if relative differences in status exist between such researchers and those they wish to influence. In addition, Levin (2004) contends that access may be driven by chance and one commonly experienced problem is that researchers are often frustrated in their efforts by not knowing who to attempt to influence.

In addition to the internal and external factors set out above, an additional thematic division of the literature emerged, highlighting two factors which are contextualising. That is, 
two factors that appear to provide a framework within which the internal and external factors operate. The first contextualising factor is whether the research relates to an idea currently favoured by policy-makers (Gladwell 2000; Kirst 2000; Landry, Amara, and Lamari 2003; Cohn 2006; Levin 2008). This is because if a study is situated within, or contributes towards, a concept which policy-makers are interested in enshrining as policy, then there is more chance that it will be adopted by policy-makers than if it does not (for example, if the study relates to a subject that is lacking in ideological or political relevance).

The term 'privileged' researcher was introduced in Brown (20II) to describe any knowledge producer who can quickly and easily access policy-makers (either because they work with or are favoured by them) and so encompasses a range of policy actors: for example, government or 'insider' researchers (Brown 2009) or (previously privileged before 2010), those identified by Ball $(2008,104)$ as the 'intellectuals of new labour'. As a result, it is argued that a second contextualising factor is the strength and nature of the relationship between researchers and policy-makers, recognising that this changes over time (Stronach and MacLure 1997; Rich 2005; Cohn 2006; Davies 2006; Ball 2008; Exley 2008; Ball and Exley 2010). Thus, researchers with strong, possibly ideologically related, ties to policy-makers may have certain perceived organisational or sector-level salience and so more chance of gaining access to and having their research considered by policy-makers, than those who do not. Whilst related to a number of the external factors above, this contextualising factor can be, and is, differentiated from them. In part, this is due to the different relationships it is possible for researchers to have with policy-makers: for instance, a researcher may simply be a provider of a contracted piece of research, won via tender process; alternatively they may be a trusted advisor and ideological advocate or openly sympathetic to the government; they may even be the friend of the policy-maker concerned. Thus, a researcher may be credible and respected (a vital external factor) but may not have a 'carte blanche' to discuss all and any policy ideas with policy-makers. Likewise, there may be in place project-related structures which enable researchers to access policy-makers with regard to specific findings, but on other topics or areas of research, these same researchers may not have recourse to approach policy-makers directly or have their findings treated in the same way.

A third conceptualising factor also emerged but does not explicitly form part of the model detailed in Figure ii below. This third factor considers the nature of the relationship that is required between policy-makers and researchers in order that knowledge adoption activity might flourish. The main gist of this factor is that successful knowledge adoption is dependent upon positive actions/strategies being employed by both narrators of, and audiences for, research outputs. In other words, the successful adoption of knowledge requires partnership working between researchers and policy-makers, with each being required to play their part in negotiating the internal, external factors set out above. This factor is typified, for example, by the work Dowling $(2005,2007,2008,2008$ a) who argues that the key phenomena of interest in the social world are the relationships between social actors. In particular, Dowling argues that the strategies employed by social actors will be invariably geared towards developing partnerships with others or towards preventing their occurrence. This third factor then provides the motivating sociological driver of knowledge adoption: building on the work of Dowling, knowledge adoption is only likely to occur when both researcher and policy-maker are actively seeking to engage with one another. This requirement for a combined positive effort, however, also removes the need to further consider this contextualising factor: knowledge adoption occurs as the result of attempts to establish relationships, as such, any model or conceptualisation of knowledge adoption can only be based upon the consideration of positive rather than negative actions (where, in the case of the latter, knowledge adoption cannot be realised). 


\section{A new model of research adoption}

Having identified these themes and their component factors, they then needed to be combined with a way that successfully explains knowledge adoption; that is, in a way that encapsulated the process whilst also accounting for the main critiques of previous models. Because of the nature of the two contextualising factors, that is, that they provide a framework for the internal and external factors, their role in the process was considered first. From the descriptions provided above, it is posited that each contextualising factor is binary in nature: that is, either the idea to which the research pertains is favoured or it isn't and the researcher either has strong ties with policy-makers or they don't. Given their context providing role, viewing these two binary statements as axes provides four possible scenarios for knowledge adoption. The nature of these scenarios therefore depends on who is communicating the research, and their ties to policy-makers, and whether a study does or doesn't relate to an idea currently in favour with policy-makers. At the same time, knowledge adoption, as per my definition above, should be considered exclusively 'conceptual' in nature. This means that I explicitly accept that evidence rarely has a directly attributable impact on policy. Thus, these scenarios present ways in which researchers can seek to enlighten policy-makers.

It is argued that the complexity of the knowledge adoption process will vary with each of these four scenarios: this complexity is expressed by differentiating, within each scenario, between those internal and external factors that may be considered crucial to the process

\begin{tabular}{|c|c|c|}
\hline & $\begin{array}{l}\text { Idea currently favoured by UK } \\
\text { policy makers }\end{array}$ & $\begin{array}{l}\text { Idea not in favour with UK } \\
\text { policy makers }\end{array}$ \\
\hline $\begin{array}{l}\text { Communicated by those with } \\
\text { strong relationships with } \\
\text { policy makers }\end{array}$ & $\begin{array}{l}\text { Scenario } 1 \\
4 \text { crucial factors } \\
\text { (i Most effective media; ii Nature of the } \\
\text { message; iii Clarity of presentation; iv } \\
\text { Proactivity, context and tailoring) } \\
\mathbf{5} \text { less important ones: } \\
\text { (i Creating demand for research; ii } \\
\text { Credibility of the source; iii User } \\
\text { engagement?; iv Quality of evidence; } v \\
\text { Access to policy makers) }\end{array}$ & $\begin{array}{c}\text { Scenario } 2 \\
7 \text { crucial factors: } \\
\text { (i Most effective media; ii Nature of the } \\
\text { message; iii Clarity of presentation; iv } \\
\text { Proactivity, context and tailoring; } v \\
\text { Creating demand for research; vi User } \\
\text { engagement?; vii Quality of evidence) } \\
\mathbf{2} \text { less important ones: } \\
\text { (i Credibility of the source; ii Access to } \\
\text { policy makers) }\end{array}$ \\
\hline $\begin{array}{l}\text { Communicated by those with } \\
\text { weak relationships with policy } \\
\text { makers }\end{array}$ & $\begin{array}{c}\text { Scenario } 3 \\
8 \text { crucial factors: } \\
\text { (i Most effective media; ii Nature of the } \\
\text { message; iii Clarity of presentation; iv } \\
\text { Proactivity, context and tailoring; v User } \\
\text { engagement? vi Quality of evidence; vii } \\
\text { Credibility of the source; viii Access to } \\
\text { policy makers) } \\
1 \text { less important one: } \\
\text { (Creating demand for research) }\end{array}$ & $\begin{array}{c}\text { Scenario } 4 \\
9 \text { crucial factors } \\
\text { (i Most effective media; ii Nature of the } \\
\text { message; iii Clarity of presentation; iv } \\
\text { Proactivity, context and tailoring; } v \\
\text { Creating demand for research; vi } \\
\text { Credibility of the source; vii User } \\
\text { engagement?; viii Quality of evidence; ix } \\
\text { Access to policy makers) }\end{array}$ \\
\hline
\end{tabular}

Figure I. Factors that affect the adoption of research (from Brown 20I2b). 
and those which are less important. For example, it has been shown that policy-makers are most likely to be receptive to research where the underpinning idea is in favour (either politically or ideologically). The crucial factors for a researcher with strong relationships with policy-makers to consider in disseminating such research, therefore, are those internal factors associated with its effective communication; the other knowledge adoption factors detailed above, whilst relevant, are less important because they have been pre-negotiated or dealt with by dint of the researcher/research's position viz-a-viz the contextualising factors (this set out in Figure I as Scenario I). The diametrically opposite position (Scenario 4) is considered to be where a researcher with a weak relationship with policy-makers is attempting to disseminate knowledge to policy-makers where the underpinning research does not relate to ideas currently in favour. Here, as well as the internal factors associated with effective communication, the researcher also has to consider relevant external factors controlled by policy-makers: how to situate evidence in order to create a demand for it; how the perceived credibility of the source can be maximised, whether the audience has been engaged in policy networks or other forms of user engagement; how to demonstrate or account for the quality of the evidence; and, how to gain access to policy-makers. As a result, it is argued that the process of researchers, with strong ties to policy-makers and disseminating favoured research to them, may be considered far less difficult than processes associated with a weakly connected researcher attempting to inject unfavoured ideas into the policy-making process (in addition intermediate positions also exist: scenarios 2 and 3). Scenarios and factors are set out in full in Figure $\mathrm{I}$.

It is argued that Figure I significantly improves upon the way in which the knowledge adoption process is currently conceived. For example, combining the assumption that knowledge adoption is dependent upon researchers and policy-makers attempting to form relationships with the notion that the effective adoption of research is a function of factors which are either internal, external or contextualizing, provides the 'why' which, up until now, has been missing: whereas existing models, such as Demand pull represent knowledge as something adopted transferred exchanged through chains or flows and via mechanics, it can be claimed that this type of representation is concerned solely with process. The model illustrated in Figure I, on the other hand, represents a different conceptualisation; that knowledge flows can only come into being and made to work if both the motivations and actions of policy-makers/researchers are simultaneously directed towards this end goal.

The 'how' of knowledge adoption is also further developed: in representing knowledge adoption as a function of both internal or external factors, the model illustrates the hurdles that researchers will need to develop successful strategies to negotiate if they are to communicate effectively or disseminate evidence to policy-makers and vice versa for policymakers attempting to act as effective audiences. At the same time, Figure I illustrates should they wish to develop policy without being encumbered with what might be viewed as inconvenient research messages, the ways through which policy-makers can seek to undermine any value research evidence might provide. For example, interview data in Brown (20II) revealed that policy-makers often promote a 'deficit' model of research; that is, the view that it is researchers alone who are responsible to the failure of any actualisation of evidence-informed policy (Perry et al. 2010). This then means that policy-makers can target factors such as the 'quality of the evidence', the 'clarity of presentation', the 'nature of the message', etc. as specific reasons for not taking on board the findings of a given study.

In utilizing the contextualizing factors, Figure I also illustrates how the actual communicator of the research and, correspondingly, their position with regard to policy-makers has as much a role to play in determining whether knowledge adoption will occur, as the nature of 
the research (i.e. whether it relates to an idea currently favoured by policy-makers). As such, unlike past models of knowledge adoption, the model highlights the differences in complexity that accrue depending upon the situation at hand, rather than assuming equality in all situations. Accordingly, it is suggested that knowledge adoption becomes easier when power is afforded to researchers (i.e. they are privileged) or power is afforded to the idea to which their research pertains. That four scenarios are presented also suggests that the situations researchers and policy-makers will find themselves in can change; this reflects comments by Rickinson, Sebba, and Edwards (20lI) who note that it may be considered simplistic to see the policy community as homogenous in terms of its likelihood to value or embrace evidence. Similarly, it can also be regarded as simplistic to assume that individual policy-makers will treat all research as equally valid and so will adopt all findings, whether or not such research sits within the paradigms of the epistemologies and ideologies which are acceptable to policy-makers.

\section{Conclusions}

The process of knowledge adoption and its efficacy should be considered essential precursors to the development of evidence-informed policy. Understanding adoption as a process: how it operates and how efforts in this area can be improved, is vital, both for researchers wishing to influence policy, and for policy-makers seeking to improve the efficacy, effectiveness and equitability of their policies (Oxman et al. 2009). Within this paper, it is argued that existing models of knowledge adoption fail to fully capture the complexities and social nature of the process. This has led to the conceptualisation of a new way of thinking about knowledge adoption (through engaging with relevant and recent literature).

It is argued that the resulting model represents a clear and distinctive perspective from that provided by existing frameworks. In doing so, it can be argued that the model meets the requirements set out by Cooper and Levin $(2010,15)$, who request that conceptualisations of research use 'move past formulations such as 'research use is complex and multifaceted', to describe that complexity and its component elements so that these can be analysed and assessed'. As a result, Figure I may be seen to move current understandings of research adoption to a point where 'we can design and implement more effective interventions that target the areas that have the greatest potential to improve systems' (ibid). It is also noted, however, that empirical research in this area would also improve upon what has been presented. In particular, to examine whether the model encapsulates all extant factors affecting the knowledge adoption process. Strategies to meet the challenges presented by these scenarios are also required; for example, use of the media or brokerage. Some of these are considered and introduced in Brown (2012a).

\section{Notes}

I. It was recognised within the original project, from which this paper is derived, that policymakers are not homogenous in nature. As such, those considered comprise Ministers and Civil Servants operating within central government. Similarly in the empirical stage of the study (not covered by this paper) researchers were differentiated with regards to their stance on whether and how evidence can inform policy.

2. See: http://www.oise.utoronto.ca/rspe/KM_Products/Terminology/index.html.

3. The report's presentation style maybe quickly ascertained via: http://mckinseyonsociety.com/ how-the-worlds-best-performing-schools-come-out-on-top/. 


\section{Notes on contributor}

Chris Brown completed his DPhil in $201 \mathrm{I}$ (at the University of Sussex) and is currently a John Adams Research Fellow at the Institute of Education. Previous to this, he was the head of Research at the Training and Development Agency for Schools. His research interests include evidence-informed policy and practice, knowledge mobilisation and notions of competence in relation to these. Recent related articles include Exploring the concepts of knowledge adoption and conceptual impact: Implications for educational research submissions to the Research Excellence Framework (20I4), Evidence, Knowledge and Economy Journal. His book, Making evidence matter, will be published in the Autumn of 2013 by IOE Press.

\section{References}

Amara, N., M. Ouimet, and R. Landry. 2004. New evidence on instrumental, conceptual, and symbolic utilization of university research in government agencies. Science Communication 26, no. I: 75-106.

Ball, S. 1995. Intellectuals of technicians? The urgent role of theory in educational studies. British Journal of Education Studies 43, no. 3: 255-7I.

Ball, S. 2008. The education debate. Bristol: The Policy Press.

Ball, S., and S. Exley. 2010. Making policy with 'good ideas': Policy networks and the 'intellectuals' of New Labour. Journal of Education Policy 25, no. 2: |5|-69.

Barber, M., and M. Mourshed. 2007. How the world's best performing school systems come out on top. London: McKinsey and Company. http: //www.mckinsey.com/clientservice/socialsector/resources/pdf/ Worlds_School_systems_final.pdf (accessed November 14, 20II).

Best, A., and B. Holmes. 2010. Systems thinking, knowledge and action: Towards better models and methods. Evidence and Policy: A Journal of Research, Debate and Practice 6, no. 2: 145-59.

Brown, C. 2009. Effective research communication and its role in the development of evidence-based policy making. A case study of the Training and Development Agency for Schools. MRes diss., University of London, Institute of Education.

Brown C. 20II. What factors affect the adoption of research within educational policy making? How might a better understanding of these factors improve research adoption and aid the development of policy? DPhil diss., University of Sussex.

Brown, C. 2012a. Exploring the concepts of knowledge adoption and conceptual impact: Implications for educational research submissions to the Research Excellence Framework (2014). Evidence, Knowledge and Economy Journal 5, no. 3: 137-54.

Brown, C. 2012b. The 'policy-preferences model': A new perspective on how researchers can facilitate the take-up of evidence by educational policy makers. Evidence \& Policy: A Journal of Research, Debate and Practice 8, no. 4: 455-72.

Campbell, S., S. Benita, E. Coates, P. Davies, and G. Penn. 2007. Analysis for policy: Evidence-based policy in practice. London: HM Treasury.

Cohn, D. 2006. Jumping into the political fray: Academics and policy making. IRPP Policy Matters 7, no. 3: $|-3|$.

Cooper, A., and B. Levin. 2010. Some Canadian contributions to understanding knowledge mobilization. Evidence and Policy: A Journal of Research, Debate and Practice 6, no. 3: 35I-69.

Cooper, A., B. Levin, and C. Campbell. 2009. The growing (but still limited) importance of evidence in education policy and practice. Journal of Educational Change 10, no. 2-3: |59-7|.

Council for Science and Technology. 2008. How academia and government can work together. London: DIUS.

Court, J., and T. Young. 2003. Bridging research and policy: Insights from 50 case studies. London: ODI.

Davies, P. 2004. Is evidence-based government possible? Jerry Lee lecture to Campbell Collaboration Colloquium, Washington DC, 19 February 2004. http: //www.policyhub.gov.uk/downloads/JerryLeeLecture I20204I.pdf\#page $=$ I (accessed November 14, 201 I).

Davies, P. 2006. Scoping the challenge: A systems approach. National forum on knowledge transfer and exchange, Toronto Canada, 23-24 October 2006. http://www.chsrf.ca/other_documents/event_reports/pdf/philip_davies.ppt.pdf (accessed November 14, 20I I).

Davies, H., S. Nutley, and P. Smith. 2000. What works? Evidence-based policy and practice in public services. Bristol: The Policy Press.

Dowling, P. 2005. Treacherous departures. http: //homepage.mac.com/paulcdowling/ioe/publications/ dowling2005/TreacherousDepartures.pdf (accessed November 14, 2010). 
Dowling, P. 2007. Organising the social. http: //homepage.mac.com/paulcdowling/ioe/publications/dowling2007.pdf (accessed November 14, 2010).

Dowling, P. 2008a. Unit 4 Generating a research question. In Research and the theoretical field lecture pack and reading pack. London: University of London.

Dowling, P. 2008b. Mathematics, myth and method: The problem of alliteration. http: //homepage.mac. com/paulcdowling/ioe/publications/dowling2008a.pdf (accessed November 14, 201 I).

Dunn, W. 1980. The two communities metaphor and models of knowledge use. Knowledge: Creation, Diffusion, Utilisation I: 5I5-36.

Edwards, A., J. Sebba, and M. Rickinson. 2007. Working with users: Some implications for educational research. British Educational Research Journal 33, no. 5: 647-6I.

Estabrooks, C., D. Thompson, J. Lovely, and A. Hofmeyer. 2006. A guide to knowledge translation theory. The Journal of Continuing Education in the Health Professions 26: 25-36.

Exley, S. 2008. The politics of specialist school policy making in England. London: University of London.

Foucault, M. 1980. Power/Knowledge: Selected interviews and other writings, 1972-1977. New York, NY: Pantheon.

Gilchrist, A. 2000. The well-connected community: Networking to the 'edge of chaos'. Community Development Journal 36, no. 3: 264-75.

Gladwell, M. 2000. The tipping point: How little things can make a big difference. London: Little Brown.

Gough, D., S. Oliver, and J. Thomas. 2012. An introduction to systematic reviews. London: Sage.

Huberman, M. 1990. Linkage between researchers and practitioners: A qualitative study. American Educational Research Journal Summer: 363-91.

Innvaer, S., G. Vist, M. Trommald, and A. Oxman. 2002. Health policy-makers perceptions of their use of evidence: A systematic review. Journal of Health Services \& Research Policy 7, no. 4: 239-44.

Kirst, M. 2000. Bridging education research and education policymaking. Oxford Review of Education 26, no. 3-4: 379-9l.

Landry, R., N. Amara, and M. Lamari. 2003. The extent and determinants of utilization of university research in government agencies. Public Administration Review 63, no. 2: 192-205.

Lavis, J., J. Lomas, M. Hamid, and N. Sewankambo. 2006. Assessing country-level efforts to link research to action. Bulletin of the World Health Organization 84: 620-8.

Lavis, J., D. Robertson, J. Woodside, C. McLeod, and J. Abelson. 2003. How can research organizations more effectively transfer research knowledge to decision makers. The Milbank Quarterly 8I, no. 2: $22 \mathrm{I}-48$.

Levin, B. 2003. Improving research-policy relationships: Lessons from the case of literacy. Paper prepared for the OISE/UT International Literacy Conference: Literacy Policies for the Schools We Need, Toronto.

Levin, B. 2004. Making research matter more. Education Policy Analysis Archives 12, no. 56: I-20.

Levin, B. 2008. Thinking about knowledge mobilization. Paper prepared for an invitational symposium sponsored by the Canadian Council on Learning and the Social Sciences and Humanities Research Council of Canada, 15-18 May.

Levin, B. 20I I. Mobilising research knowledge in education. London Review of Education 9, no. I: I5-26.

Lindblom, C., and D. Cohen. 1979. Usable knowledge: Social science and social problem solving. New Haven, CT: Yale University Press.

Mitton, C., C. Adair, E. McKenzie, S. Patten, and B. Waye-Perry. 2007. Knowledge transfer and exchange: Review and synthesis of the literature. The Milbank Quarterly 85, no. 4: 729-68.

Moore, G., S. Redman, M. Haines, and A. Todd. 20II. What works to increase the use of research in population health policy and programmes: A review. Evidence and Policy: A Journal of Research, Debate and Practice 7, no. 3: 277-305.

Nutley, S.M., H.T.O. Davies, and I. Walter. 2002. Learning from the diffusion of innovations. Edinburgh: Research Unit for Research Utilisation, University of St. Andrews.

Nutley, S.M., I. Walter, and H.T.O. Davies. 2007. Using evidence: How research can inform public services. Bristol: The Policy Press.

Nyden, P., and W. Wiewel. 1992. Collaborative research: Harnessing the tensions between researchers and practitioners. The American Sociologist 23, no. 4: 43-45.

Oakley, A. 2003. Research evidence, knowledge management and educational practice: Early lessons from a systematic approach. London Review of Education I, no. I: 2I-33.

Oancea, A., and J. Furlong. 2007. Expressions of excellence and the assessment of applied and practicebased research. Research Papers in Education 22, no. 2: 119-37. 
Oh, C. 1997. Explaining the impact of policy information on policy-making. Knowledge and Policy 10, no. 3: $25-55$.

Oxman, A., Lavis, J., Lewin, S., and A. Fretheim. 2009. SUPPORT Tools for evidence-informed health Policymaking (STP) I: What is evidence-informed policymaking? http://www.health-policy-systems. com/content/7/SI/SI (accessed November I4, 20I0).

Paisley, W. 1993. Knowledge utilization: The role of new communications technologies. Journal of the American Society for Information Science 44, no. 4: 222-34.

Perry, A., Amadeo, C., Fletcher, M., and E. Walker. 20I0. Instinct or reason: How education policy is made and how we might make it better. Reading: CfBT.

Rich, R. 199I. Knowledge creation, dissemination, and utilisation. Knowledge: The International Journal of Knowledge Transfer and Utilisation 12, no. 3: 319-37.

Rich, A. 2005. Think tanks, public policy and the politics of expertise. Cambridge: Cambridge University Press.

Rickinson, M., J. Sebba, and A. Edwards. 201I. Improving research through user engagement. London: Routledge.

Sandelowski, M., Voils, C., Leeman, J., and J. Crandell. 20II. Mapping the mixed methods-mixed research synthesis terrain. Journal of Mixed Methods Research. https://portal.ioe.ac.uk/http/mmr.sagepub.com/content/early/recent (accessed January 7, 20I2).

Sylva, K., B. Taggart, E. Melhuish, P. Sammons, and I. Siraj-Blatchford. 2007. Changing models of research to inform educational policy. Research Papers in Education 22, no. 2: 155-68.

Taggart, B., I. Siraj-Blatchford, K. Sylva, E. Melhuish, and P. Sammons. 2008. Influencing policy and practice through research on early childhood education. International Journal of Early Childhood Education 14, no. 2: 7-21.

Temple, P. 2003. Educational research and policymaking: Findings from some transitional countries. London Review of Education I, no. 3: 217-28.

Watson, D., R. Townsley, D. Abbott, et al. 2002. Exploring multi-agency working in services to disabled children with complex healthcare needs and their families. Journal of Clinical Nursing II: 267-79.

Weiss, C. 1979. The many meanings of research utilisation. Public Administration Review 29: 426-31.

Weiss, C. 1982. Research in the context of diffuse decision making. The Journal of Higher Education 53, no. 6: 619-39.

Weiss, C. 1998. Have we learnt anything new about the use of evaluation? American Journal of Evaluation 19, no. I: 12-3.

Wingens, M. 1990. Toward a general utilization theory: A systems theory reformulation of the twocommunities metaphor. Knowledge, September, 27-42.

Yin, R.K., and G.B. Moore. 1988. Lessons on the utilisation of research from nine case study experiences in the natural hazards field. Knowledge in Society: The International Journal of Knowledge Transfer I, no. 3: 25-44. 